\title{
RESENHA
}

\section{For the soul of mankind: the United States, the Soviet Union, and the Cold War*}

ROGÉRIO DE SOUZA FARIAS**

Melvyn Leffler é um prolífico autor, tendo já redigido centenas de páginas sobre a Guerra Fria. Seu livro sobre a doutrina de segurança nacional do governo Truman é um dos maiores trabalhos sobre a política externa americana do século XX; seus embates com o historiador John Lewis Gaddis são igualmente relevantes para a historiografia americana. Tendo se dedicado tanto ao tema, podemos nos perguntar por que esse autor decidiu escrever outro livro sobre a Guerra Fria.

São duas razoes que justificam a publicação de mais um volume sobre o período. A primeira é que o autor, assim como outros estudiosos do período, não previu o fim do conflito. Subitamente, o mundo no qual ele vivia e estudava deixara de existir. Poucas pessoas anteciparam o fim; um grupo menor ainda de indivíduos conseguiu predizer em quais condições e como essa transição se daria. Para Leffler, além do desafio de entender por que o conflito terminou, há uma outra questão subjacente bem mais complexa e que merece um exame mais detido: se a Guerra Fria terminou ao final da década de 1980 em um processo aparentemente tão simples, por que isso não ocorreu antes? A resposta a essa pergunta, no fundo, traz os benefícios analíticos de se examinar dinâmicas causais como forma de entender a duração do conflito. A segunda razão para o autor desejar redigir outro livro sobre a Guerra Fria está no volume de fontes primárias crescentemente disponível aos estudiosos. Desde a década de 1990, toneladas de documentos da URSS, da China e da Europa Oriental começaram a ser disponibilizados para pesquisadores do ocidente. Há memorandos de conversas de Stalin com líderes comunistas da Europa Oriental; há notas de reuniōes do Politburo com Khrushchev do final da década de 1950 e início da década de 1960; há registros de conversas de Brezhnev com membros do Pacto de Varsóvia; há minutas das discussões dos líderes soviéticos sobre a invasão do Afeganistão em 1979; há, inclusive, as transcrições de todas as conversas de Reagan com Gorbachev.

\footnotetext{
* LEFFLER, Melvyn P. For the soul of mankind: the United States, the Soviet Union, and the Cold War. New York: Hill and Wang, 2007, 586 p., ISBN: 978-0-8090-9717-3.

** Mestre em Relaçôes Internacionais pela Universidade de Brasília - UnB (rofarias@gmail.com).
} 
Dois aspectos da documentação intrigaram Leffler. O primeiro foi que os líderes soviéticos realmente acreditavam que eles estavam criando uma civilização superior, uma melhor forma de organizar a experiência humana - não era, portanto, uma retórica, como muitos analistas ocidentais chegaram a acreditar. Os soviéticos tinham uma crença arraigada de que tinham criado um sistema melhor para responder aos anseios de sua população. Eles estavam, enfim, travando uma luta pela "alma da humanidade", como também estavam os americanos. O segundo aspecto que surpreendeu o autor foi que líderes em Moscou, assim como em Washington, comumente percebiam que a lógica da Guerra Fria era contra-producente, minava os próprios interesses nacionais e desviava recursos e atenção de prioridades domésticas. Isso era ainda mais nítido quando esses indivíduos observavam que o conflito os levavam a intervir em outros países que não tinham relação alguma com os respectivos interesses vitais. O que fica claro na documentação é que esse núcleo de idéias predispôs diversas vezes as elites políticas de ambos os países a acreditar que a cooperação era melhor do que a Guerra Fria (p. 4-5).

O primeiro objetivo do autor, então, foi criar uma narrativa que expusesse cinco ocasiōes históricas nas quais houve intenções em Moscou e em Washington de diminuir a instabilidade de rivalidade, de desengajamento ou de por fim ao conflito. A primeira foi a relação entre Truman e Stalin no imediato pósguerra - ambos os líderes demonstravam grande interesse em dar continuidade à relação de cooperação que existia até então; Stalin, inclusive, defende essa tese com políticos da Europa Oriental. A segunda é sobre o período 1953-54, logo após a morte de Stalin - a insegurança dos líderes soviéticos levou-os a tentar diminuir a tensão da Guerra Fria, tendo ocorrido respostas positivas por parte dos americanos, inclusive de Eisenhower. A terceira ocorreu logo após a Crise dos Mísseis, entre Kennedy (depois Johnson) do lado americano e Khrushchev do lado soviético - o perigo de uma hecatombe nuclear impulsionou uma séria iniciativa para se repensar o relacionamento bilateral dos dois países. A quarta veio com Carter e Brezhnev, em meados da década de 1970 - eles trabalharam duramente para sustentar e aprimorar a détent após os acordos de Helsinque. A última oportunidade veio com Gorbachev e Reagan, na década de 1980 - percebia-se que a posse de armas nucleares não fazia sentido algum e que os dois países deveriam fazer o possível para acabar com a irracional corrida armamentista.

A grande questão que o autor procura responder é por que nos primeiros quatro casos as tentativas de modificar ou terminar o conflito fracassaram, enquanto Gorbachev e Reagan conseguiram sucesso. A chave para entender não só a Guerra Fria, mas também a sua continuação por mais de quatro décadas estaria em um conjunto de variáveis que Leffler explora em todos os capítulos. A primeira é que as condições internacionais nas quais os decisores operavam não podiam ser controladas, muito menos reformuladas. Esse marco 
contextual, para Leffler, era tão poderoso que cerceava até os ímpetos mais sinceros de colaboração entre os dois países. O fim da II Guerra na Europa, por exemplo, criou percepções de riscos - o vácuo de poder decorrente do colapso da Alemanha e do Japão introduzia apreensões sobre o futuro que constrangiam os líderes políticos de então. A segunda foi o longo processo de descolonização, que perdurou por três décadas. Aqui, também, há o surgimento de crenças em Moscou e Washington que minaram a colaboração - havia chances de capitalização clientes no Terceiro Mundo, o que gerava desconfianças recíprocas entre as duas potências. O sistema internacional, destarte, oferecia oportunidades demasiadamente interessantes para serem ignoradas. A terceira foi que o conjunto de percepções dos decisores era moldado tanto pela ideologia como pela memória histórica - entendimentos específicos sobre a história e sistemas de valores criavam animosidades entre as elites decisórias. A quarta é a natureza da política doméstica e das instituições nacionais, e como essas limitaram os espaços de ação dos líderes políticos - um exemplo interessante está no trecho "agonias e escolhas de Johnson", no terceiro capítulo, quando Leffler mostra que o presidente americano, mesmo avisado que o premiê soviético estava em Hanói, decide bombardear o Vietnã naquele momento porque temia seriamente, na época, as críticas de seus adversários domésticos. Esses constrangimentos também existiam na União Soviética de Brezhnev. O líder soviético era um entusiasta da détente, mas não conseguia controlar os desejos de sua burocracia, muito menos do Exército, ambos seduzidos pelos prospectos que se abriam tanto em Angola como no Afeganistão. A quinta variável é a forma pela qual a pressão de aliados e clientes pressionou e constrangeu os desejos de soviéticos e americanos em aproveitar oportunidades de colaboração. Havia, dessa maneira, na periferia do sistema internacional, diversos países que não desejavam que a belicosidade da Guerra Fria arrefecesse, pois a dinâmica do conflito os favoreciam.

O foco do trabalho é essencialmente nas lideranças mais altas das duas grandes potências, especialmente nos traços de personalidade de pares como Stalin e Truman, Eisenhower e Malenkov, Kennedy (posteriormente Johnson) e Khrushchev, Brezhnev e Carter, Gorbachev e Reagan (posteriormente Bush). A forma pela qual se reproduziam lógicas de cooperação e conflito no ambiente em que esses líderes operavam até a década de 1980 fez com que não fosse possível transcender o padrão de desconfiança e belicosidade. Eles não conseguiam se livrar dos constrangimentos impostos pelo sistema internacional, pela política doméstica e pelas respectivas predisposições ideológicas e cognitivas.

Essa situação mudou na década de 1980. Um arranjo estável para a Alemanha deixara de ser um problema, a descolonização terminara seu ciclo, o ímpeto revolucionário de mais de três décadas mudara o cálculo de ameaça da balança de poder no Terceiro Mundo e a política doméstica não mais era a mesma. Reagan e Gorbachev atuavam em um contexto diferente do que havia sido presenciado pelos seus antecessores. Os constrangimentos, barreiras que 
impediram as iniciativas anteriores, não mais estavam presentes para obstruir tentativas de reconstrução da lógica do conflito. Somente nesse ambiente foi possível diminuir a tensão do conflito e depois terminá-lo.

A conclusão de Leffler é que não foi o poder militar que ganhou a guerra fria, muito menos a política externa dos Estados. Eles foram importantes, mas não críticos. O Ocidente ganhou a Guerra Fria pelo fato de o capitalismo ter superado um sistema centralizado de mobilização de recursos. Uma segunda conclusão foi que a negociação foi um elemento central para o término da Guerra Fria - aqui, o foco recai principalmente no relacionamento entre Reagan e Gorbachev. O terceiro é que, ao se redigir qualquer trabalho em relações internacionais, devemos integrar nas nossas narrativas a estrutura do sistema internacional com uma análise da ideologia, da memória histórica e da política doméstica, ressaltando principalmente o papel da ação humana.

O livro é muito bem redigido. A narrativa é bastante agradável aos leitores, principalmente aos mais jovens - é um daqueles volumes dos quais não conseguimos nos separar até a leitura da última frase. Mas há alguns problemas. Primeiro, apesar da eloqüente asserção de que as novas fontes disponíveis trouxeram novas interpretações sobre a Guerra Fria, o volume não traz uma revolução à historiografia do período. Muito do que é considerado novidade já foi apresentado em livros, artigos de periódicos - principalmente do Journal of Cold War Studies - ou em memórias. Segundo, Leffler, na introdução do volume, faz uma crítica velada aos acadêmicos que colocam as características dos homens de estado como elementos explicativos centrais da história da Guerra Fria. Mas, mesmo considerando os importantes elementos analíticos que ele traz para a narrativa, os homens de estado continuam sendo o eixo central no qual ele examina a evolução do período - do perfil biográfico de Stalin, no primeiro capítulo, até o de Reagan, no último, a unidade de análise do livro pouco se expande para outras forças. A desconexão entre propósito e resultado fica mais nítida quando chegamos à conclusão. Leffler demonstra que Reagan e Gorbachev são elementos centrais para se entender o fim da Guerra Fria (p. 461-465); mas, ao mesmo tempo, também fica claro que foram forças econômicas, principalmente a percepção das mudanças que ocorriam no sistema capitalista, e não a negociação ou a política externa que, no fim, trouxeram o fim do conflito (p. 370, 388,417, 459-460 e 463). Isso é algo importante, pois, durante quase todo o livro, as forças econômicas estão fora do proscênio narrativo do autor - é na negociação e na política externa que os acontecimentos centrais se desdobram.

Mesmo com esses problemas, o autor demonstra habilmente que a Guerra Fria não foi pré-determinada. Os líderes fizeram escolhas e o conflito sustentouse por tanto tempo pelo fato de esses indivíduos terem sido aprisionados por suas idéias, pelos constituintes e burocracias domésticas, pelas demandas de aliados e clientes e, sobretudo, pela dinâmica do sistema internacional. Foi por conta 
dessa configuração de forças que as oportunidades de diminuir a latitude ou até mesmo acabar com o conflito, durante mais de quarenta anos, foram perdidas. A leitura do trabalho, por fim, é instrutiva por sua estrutura narrativa que pode servir de exemplo para o exame de outros casos de "oportunidades perdidas" por exemplo, a dinâmica de cooperação e conflito do relacionamento bilateral entre Brasil e Argentina no século XX. 